\title{
Entre femininos e masculinos: negociando relações de gênero no campo político"
}

\begin{abstract}
Alinne de Lima Bonetti*
Resumo

A análise da prática política cotidiana de um grupo de Promotoras Legais Populares - mulheres das camadas populares porto-alegrenses formadas no curso de capacitação em Direitos Humanos das Mulheres - permite perceber os diferentes atributos de gênero que sua participação no contexto político de Porto Alegre revela. Estas mulheres negociam e produzem contextualmente novas relações de gênero num campo político constituído por atributos culturalmente associados ao masculino, seja no embate entre diferentes femininos, seja na apropriação e atualização de atributos masculinos. A partir da etnografia junto a este grupo de mulheres, este texto traz uma reflexão sobre como a sua prática política engendra diferentes relações de gênero no contexto político de Porto Alegre.
\end{abstract}

Palauras-chave: Relações de Gênero, Participação Política, Mulheres.

\footnotetext{
* Recebido para publicação em setembro de 2002.

*** Doutoranda em Ciências Sociais - Área de Família e Relações de Gênero -, Unicamp.alinnebonetti@hotmail.com
}

cadernos pagu (20) 2003: pp.177-203 
Relações de gênero no campo político

Between Feminine and Masculine:

Negotiating Gender Relations in the Political Field

\begin{abstract}
Analysing the daily political practices of a group of Legal Advocates women of the working strata of Porto Alegre that followed the capacitation course in Human Rights - I was able to notice the different gender attributes revealed by their taking part in Porto Alegre's political context. These women negotiate and produce contextually new gender relations in a political field constituted by attributes culturally associated with the masculine. They do so either in the clash between different feminines or in the appropriation and instantiation of attributes of masculines. From the ethnography I undertook among this group of women, I propose a reflection on how their political practice generates different gender relations in Porto Alegre's political context.
\end{abstract}

Key Words: Gender Relations, Political Participation, Women. 


\section{Introdução}

Cada vez mais se nota a presença de mulheres no mundo da política $e$ a visibilidade desta crescente presença introduz a expressão de uma diversidade de relações e de atributos de gênero. Mais especificamente, no contexto político de Porto Alegre tal presença se torna mais explícita com a emergência, cada vez maior, da participação política de mulheres de camadas urbanas de baixa renda. De resto, o aumento desta participação política não se dá por acaso.

Ao longo dos últimos 12 anos, a configuração política da cidade de Porto Alegre tem levado à consolidação de uma cultura política calcada na participação popular. O que significa dizer que na base desta configuração está um projeto voltado para o incentivo da participação dos cidadãos nos processos políticos da cidade. Tal incentivo tem como um dos seus objetivos a democratização $e$ a superação das relações sociais de desigualdade, através da inclusão da população de baixa renda no processo político, do que decorre a ênfase no "popular". ${ }^{1}$ Desta configuração política particular resultou a constituição da cidadania e da participação política como grandes valores sociais e o aparecimento de diversos canais para o exercício desta participação. Dentre estes canais de participação política destacam-se o Orçamento Participativo, os Conselhos Tutelares, os inúmeros conselhos municipais, as entidades da sociedade civil voltadas para a promoção da igualdade e da cidadania. ${ }^{2}$

1 Pereira Neto, Francisco de. Assistência social e caridade: religião, política e a experiência da solidariedade em Porto Alegre. Tese de Doutorado em Antropologia Social, Universidade Federal do Rio Grande do Sul, Porto Alegre, 2001, 400p.

2 Fedozzi, Luciano. Orçamento participativo: reflexóes sobre a experiência de Porto Alegre. Porto Alegre, Tomo Editorial, 1997; NAVARRO, Zander. Uma análise do Orçamento Participativo: sua implantação e desenvolvimento. In: GENRO, Tarso. (coord.) Porto da cidadania: a esquerda no governo de Porto Alegre. Porto Alegre, Artes e Ofícios, 1997; RIBEIRO, Fernanda. A inserção do Conselho Tutelar na construção do problema social da infância e da adolescência: um 
Relações de gênero no campo político

A questão que se coloca aqui é se a crescente participação política de mulheres introduziria alguma peculiaridade nas relações de gênero neste contexto político. Ou, mais especificamente, quais seriam as implicações desta participação política na negociação e na transformação das relações de gênero e de poder neste campo de disputas?

A reflexão sobre estas questões parte de um estudo sobre o significado da participação política para um grupo de mulheres das camadas de baixa renda de Porto Alegre - as Promotoras Legais Populares (PLPs). ${ }^{3}$ As PLPs são ativistas dos Direitos Humanos das Mulheres, ligadas ao projeto de intervenção social da ONG feminista gaúcha Themis - Assessoria Jurídica e Estudos de Gênero. ${ }^{4}$

O grupo pesquisado se caracteriza por possuir uma vasta trajetória no campo político ${ }^{5}$ comunitário e, através da grande

estudo de caso a partir do conselho tutelar da Microrregião 3 de Porto Alegre. Dissertação de Mestrado em Sociologia, Universidade Federal do Rio Grande do Sul, Porto Alegre, 1996, 300p.

3 BONETTI, Alinne de Lima. Entre feministas e "mulheristas": uma etnografia sobre Promotoras Legais Populares e novas configurações da participação política feminina popular em Porto Alegre. Dissertação de Mestrado em Antropologia Social, Universidade Federal de Santa Catarina, Florianópolis, 2000, 194p.

4 O projeto "Formação de Promotoras Legais Populares", iniciado em 1993 em Porto Alegre, tem duas grandes etapas: o curso de formação, através do qual as participantes adquirem conhecimentos básicos sobre Direitos Humanos e Direitos das Mulheres, e o Serviço de Informação à Mulher (SIM). O SIM é o local de atuação das PLPs nos bairros onde vivem $e$ atendem mulheres em situação de violação dos seus direitos, em especial casos de violência doméstica. Sobre o viés político da ONG Themis e as implicações da introdução da categoria Direitos Humanos das Mulheres junto a mulheres das camadas urbanas de baixa renda, ver BONETTI, A. L. Novas configurações: Direitos Humanos das mulheres, feminismo e participação política entre mulheres de grupos populares portoalegrenses. In: NOVAES, Regina e KANT DE LIMA, Roberto. (orgs.) Antropologia e Direitos Humanos. Niterói, EdUFF, 2001.

5 O conceito de campo político utilizado ao longo do texto refere-se à definição consagrada por Bourdieu: "um campo de forças e de lutas (...) o lugar onde se geram, na concorrência entre os agentes que nele se acham envolvidos, produtos 
circulação pelos espaços políticos da cidade, chegou ao projeto da ONG. A pesquisa demonstrou que, para o grupo pesquisado, a participação política está associada a aspirações de mudança de status social e à busca pela realização de projetos individuais. Tais projetos são "elaborados e construídos em função de experiências sócio-culturais, de um código de vivências e interações interpretadas", a partir de "um campo de possibilidades, circunscrito histórica e culturalmente". ${ }^{6}$

Estes elementos marcam a novidade que esta participação política introduz ao modelo pelo qual a militância política desta parcela da população feminina foi explicada. Ao contrário do modelo da "maternidade militante" pesquisado não se motiva pela extensão dos seus tradicionais papéis de mães e esposas. Tampouco se restringe ao espaço das relações políticas comunitárias (creches, CEBs, clubes de mães, associações de bairro), a exemplo dos movimentos populares reivindicativos - palco por excelência da participação feminina popular, muito celebrada pela literatura da década de $80 .^{8}$

políticos, problemas, programas, análises, comentários, conceitos, acontecimentos. BOURDIEU, Pierre. O poder simbólico. Rio de Janeiro, Bertrand, 1989, p.164.

${ }^{6}$ VelHo, Gilberto. Individualismo e cultura: Notas para uma antropologia da sociedade contemporânea. 3a . edição, Rio de Janeiro, Jorge Zahar Editor, 1994, pp.26-27.

7 Alvarez cunhou esta definição para explicar a militância política de mulheres das camadas urbanas de baixa renda. A "maternidade militante" se define por uma atuação política pautada pelos papéis de mães e esposas - as guardiãs da coesão e bem-estar familiar - e pela reivindicação por melhores condições de vida e moradia para o bairro. AlvAREZ, Sonia. Politizando as relações de gênero e engendrando a democracia. In: STEPAN, A. (ed.) Democratizando o Brazil. Rio de Janeiro: Paz e Terra, 1988.

8 CAldEIRA, Teresa. Mujeres, cotidianidad y política. In: JELIN, E. Participación, ciudadanía e identidad: Las mujeres en los movimientos sociales latinoamericanos. Genebra, UNRISD, 1987; FILGUEIRAS, Cristina. O cotidiano das lutas urbanas: participação das mulheres na organização dos moradores do bairro Água Branca. VIII Encontro Anual ANPOCS, Águas de São Pedro, 1984; SINGER, 
Relações de gênero no campo político

A partir das peculiaridades da militância política das PLPs pesquisadas, os inúmeros canais de participação emergentes no contexto político de Porto Alegre são encarados como potenciais lugares para a sua atuação e realização dos seus projetos. Neste contexto, o projeto da ONG se apresenta como uma possibilidade, entre outras, para o exercício da participação política.

As PLPs se revelaram hábeis agentes do campo político. Elas dominavam os termos do jogo político, se inseriam em diferentes contextos, se apropriavam dos diferentes códigos que regiam os espaços semânticos que constituem o campo e se utilizavam de diferentes recursos para alcançarem o seu objetivo. ${ }^{9}$ Estabeleciam, estrategicamente, diferentes relações de acordo com os mais diversos contextos em que se encontravam. Revelavam, assim, uma "competência específica e probabilidade de sucesso no jogo propriamente político". ${ }^{10}$ Este constante jogo de inserções e de

Paul. O feminino e o feminismo. In: Singer, P. \& Brant, V. (orgs.) São Paulo: o povo em movimento. Petrópolis, Vozes/CEBRAP, 1980.

9 A expressão "espaço semântico", tal como utilizada ao longo do texto, inspirase na definição de cultura utilizada por Comaroff \& Comaroff. Para estes antropólogos, a cultura é "o espaço semântico, o campo de sinais e práticas, nos quais seres humanos interpretam e representam eles próprios e os outros, e conseqüentemente suas sociedades e histórias, [contendo] em si imagens, ações e mensagens potencialmente contestáveis e polivalentes. [Cultura] é, em suma, um conjunto em desdobramento, historicamente situado de significados em ação imediatamente material e simbólico, social e estético". COMAROFF, John and Jean. Ethnography and the Historical Imagination. Boulder, Westview Press, 1992 p.27. A utilização da noção de "espaços semânticos", no caso estudado, busca salientar algumas características peculiares. A primeira delas diz respeito à própria constituição do campo político, composto por diferentes contextos, os quais possuem códigos, valores e regras específicas. Outra se refere à dinamicidade da produção, contestação, negociação e ressignificação dos valores que dotam de sentido tais contextos do campo político através da circulação de diferentes agentes nestes contextos. Ou seja, no caso aqui estudado, na prática política cotidiana, o grupo circula por diferentes espaços semânticos do campo político, dialogando com os seus códigos e regras, contestando-os e ressignificando-os, produzindo, assim, novos significados no campo político.

${ }^{10}$ Bourdieu, P. O poder simbólico. Op. cit., p.169. 
relações fazia com que as PLPs negociassem diferentes relações de gênero, que implicavam na apropriação $e$ atualização de diferentes atributos de gênero.

Este texto está centrado na análise de como o grupo pesquisado entrava no jogo político e nele negociava e estabelecia relações de poder e de gênero, questionando em que medida sua participação política implica numa reconfiguração das relações políticas (e de poder).

A discussão se apresenta em três partes. Na primeira parte são analisados os significados de gênero que dotam de sentido o campo político no qual se inscreve a participação do grupo pesquisado. $\mathrm{Na}$ segunda parte são elencados os atributos de gênero com os quais as PLPs se inserem no campo político, que permitem discutir a configuração de um modelo de feminilidade contingente e fluído, próprio das mulheres pesquisadas. A última parte traz uma análise de como as PLPs negociam diferentes relações de gênero nas mais diversas relações políticas estabelecidas no desempenho do jogo político, através de três diferentes situações etnográficas. Esta discussão converge para o questionamento da possibilidade de transformação das relações de poder e de gênero dentro do campo político de Porto Alegre, tendo como referência o contexto do campo de lutas pelos direitos das mulheres.

\section{O gênero do político - ou sobre como o mundo da política é masculino}

Como ponto de partida é fundamental refletir sobre os sentidos de gênero que constituem o campo político. Para esta tarefa parece útil a diferenciação proposta por Alvarez entre o campo da política e o campo do político. ${ }^{11}$

${ }^{11}$ AlvareZ, Sonia. Feminismos latino-americanos. Revista Estudos Feministas, Rio de Janeiro, IFCS/UFRJ, vol. 6, nº 2, 1998, pp.265-284. 
Relações de gênero no campo político

$\mathrm{Na}$ proposta da autora, o campo da política circunscreve a esfera da política clássica. Ou seja, refere-se às instituições políticas, aos partidos políticos, aos cargos de representação política e aos espaços de atuação. O campo do político tem um sentido mais amplo, diz respeito ao "cultural, ao simbólico e às relações de poder/gênero que aí se constituem e se reconfiguram continuamente". ${ }^{12}$ Enfatizar o campo do político é uma tentativa de trazer à tona o "conjunto de significados simbólicos, visões de mundo, divisões que se explicitam em linguagens, crenças $e$ rituais" 13 , os quais atribuem sentido ao campo da política. Estas duas dimensões, intimamente associadas, aqui separadas para fins analíticos, compõem o campo político no qual se insere o caso das PLPs.

Afirmar que o campo político é um espaço semântico eminentemente masculino implica considerar os valores que o compõem (o campo do político) e seus atributos de gênero. Significa, ainda, afirmar que tais atributos, que o dotam de sentido, são culturalmente associados ao masculino. A reflexão sobre esta atribuição de sentido ao campo político foi aqui inspirada nas análises de Butler e Scott. ${ }^{14}$

Butler, ao discutir as condições de possibilidade de um "sujeito da política do feminismo", reflete sobre a constituição do sujeito autorizado e legítimo da política, ao qual denomina "sujeito ocidental masculinizado". Segundo a autora, este sujeito, entendido como a representação do sujeito da política, é aquele

\footnotetext{
${ }^{12}$ ID., IB., p.267.

${ }^{13}$ BARREIRA, Irlys. Entre mulheres: jogo de identificações e diferenças em campanhas eleitorais. In: BARREIRA, Irlys e PALMEIRA, Moacir. (orgs.) Candidatos e candidaturas: enredos de campanha eleitoral no Brasil. São Paulo, Anna Blume Editora,1998, p.132.

${ }^{14}$ BUTLER, Judith. Fundamentos contingentes: o feminismo e a questão do "pósmodernismo". Cadernos Pagu - Trajetórias do gênero, masculinidades... - (11), Campinas, 1998; SCOTT, Joan. Gênero: uma categoria útil de análise histórica. Revista Educação e Sociedade, Porto Alegre, n 16, vol. 2, jul/dez 1990, pp.5-22.
} 
que institui as regras do jogo político através do uso da força, um dos seus principais atributos de gênero.

A transposição da análise de Butler para o caso aqui estudado leva a pensar que este "sujeito ocidental masculinizado" atribui sentido de gênero ao jogo político e institui as regras e os códigos culturais a serem seguidos no campo político, a partir de atributos como força, agressividade e virilidade, associados ao masculino na cultura ocidental.

A reflexão sobre o sujeito da política é ainda mais elucidativa para o caso aqui estudado se associada à reflexão de Scott. Segundo a autora, "gênero" é uma categoria analítica conformada por duas proposições fundamentais: "o elemento constitutivo das relações sociais fundadas sobre as diferenças percebidas entre os sexos e o primeiro modo de dar significado às relações de poder". ${ }^{15}$ A categoria analítica gênero articula concepções cultural e historicamente situadas, partindo, portanto, dos significantes disponíveis na cultura. Estes significantes são apropriados pelos sujeitos sociais, os quais lhes atribuem determinados sentidos.

Segundo Scott, gênero implica na atribuição de valores culturais a diferenças percebidas, as quais significam disputas de poder sobre a definição do que pode ser culturalmente considerado legítimo e autorizado. Esta disputa de poder se traduz na contenção das possibilidades metafóricas dos símbolos representativos das diferenças percebidas, definindo-os, legitimando-os e dotando-os de sentido. Esta atribuição de sentido, por parte daquela disputa de poder, perpassa o conjunto social como um todo.

Mais precisamente, a disputa de poder atribui ao conjunto social significados de gênero. Portanto, dota de sentido de gênero o campo político - os seus valores, códigos e regras e as suas instituições e organizações. Desta forma, os atributos da

${ }^{15}$ ScOTT, J. Gênero: uma categoria útil de análise histórica. Op. cit., p.16. 
Relações de gênero no campo político

fragilidade feminina e da força masculina, parte do repertório cultural ocidental, são estendidos ao campo político.

Se considerarmos o senso comum como um sistema cultural $^{16}$, a concepção do campo político como masculino passa a ter mais sentido. O que significa dizer que os sujeitos da cultura, apreendendo os significados que são por eles mesmos construídos, passam a utilizá-los de forma coerente com seu universo de valores de referência. É importante salientar que a atribuição de sentido de gênero (de atributos masculinos) ao campo político não implica em afirmar que os homens - ao se utilizarem da sua prerrogativa biológica - sejam os únicos a terem acesso e lugar no campo político. Antes, informa sobre os valores culturais que constituem o campo.

Ao partir desta perspectiva, enfoco minha análise nas formas como o grupo pesquisado se insere no contexto político de Porto Alegre, buscando compreender as possibilidades semânticas de gênero que esta inserção revela. Parece-me situar-se aí a riqueza etnográfica da experiência política deste grupo de mulheres.

Ao se inserirem no campo político, através de um intricado jogo permeado por disputas, busca por reconhecimento $e$ legitimidade e no uso de estratégias, estas mulheres negociam $e$ produzem contextualmente novas relações de gênero. Seja no embate entre diferentes femininos, seja na apropriação $e$ atualização de atributos masculinos. No entanto, anteriormente a esta discussão, é necessário explicitar com quais atributos de gênero estas mulheres entram no jogo político.

${ }^{16}$ GEERTZ, Clifford. O saber local: novos ensaios em antropologia interpretativa. Petrópolis, Vozes, 1998. 


\section{PLPs, mulheres valentes - a especificidade de um feminino}

As PLPs pesquisadas são mulheres oriundas das camadas populares da cidade de Porto Alegre. ${ }^{17}$ Compartilham um universo de valores no qual as relações de gênero se estruturam a partir da lógica de complementaridade de papéis entre o feminino $e$ o masculino. Estes papéis possuem diferentes atribuições $e$ obrigações dentro da relação familiar, conformando o "pacto de reciprocidade conjugal".

Neste pacto, ao homem cabe o bom desempenho de seu papel ao prover a família tanto material quanto simbolicamente proteção, garantia de respeito social. À mulher cabe a fidelidade sexual, a evitação masculina (a fim de corroborar sua indisponibilidade sexual), a luta para manter seu laço conjugal e o cuidado dos filhos e da casa. ${ }^{18}$ De acordo com estes valores, é

\footnotetext{
${ }^{17} \mathrm{O}$ conceito de grupos populares aqui utilizado se inspira numa linha de estudos cujo recorte analítico enfoca a experiência de vida e os valores culturais de grupos urbanos de baixa renda. Este recorte analítico atenta para os riscos de um conceito de cultura reificada - que apresenta sistemas simbólicos como se fossem isolados e homogêneos. Procurando se afastar destes riscos, tal recorte procura, sobretudo, compreender a coerência interna de lógicas culturais distintas que convivem numa mesma sociedade. Situadas numa sociedade de classes, marcada por profundas desigualdades sociais como a nossa, tais lógicas culturais revelam modos de vida diferentes e é sobre estas diferenças que o conceito de grupos populares procura dar conta. Ver FonSECA, Claudia. Família, Fofoca $e$ honra - etnografia de relaçóes de gênero e violência em grupos populares. Porto Alegre, Editora da Universidade, 2000 e Caminhos da adoção. São Paulo, Cortez, 1995; DuARTE, Luis Fernando Dias. Da vida nervosa nas classes trabalhadoras urbanas. $2^{\text {a }}$ edição, Rio de Janeiro, Zahar, 1988; SARTI, Cynthia. $A$ familia como espelho: um estudo sobre a moral dos pobres. Campinas, Editores Associados, 1996.

${ }^{18}$ Por mais que, muitas vezes, a mulher sustente materialmente a casa sem a ajuda masculina, a presença masculina é fundamental, posto que informa sobre o status social destacado da mulher. Nestes contextos culturais "imagina-se sempre que se uma mulher está só é porque não consegue arranjar um homem". [FONSECA, Claudia. Feminino, masculino e formas de poder: o código de honra de uma vila porto-alegrense. Cadernos de Estudo. Porto Alegre, no 10, 1988, p.11]. Este aspecto eminentemente simbólico revela a complementaridade de
} 
Relações de gênero no campo político

fundamental que a mulher tenha um homem ao seu lado, bem como o homem tenha uma mulher ao seu lado para serem socialmente considerados e reconhecidos entre os seus pares.

$\mathrm{O}$ grande diferencial do grupo pesquisado, aquilo que suas experiências através da sua participação política trazem de novo, é o fato de desafiarem os limites deste pacto. Mesmo referendando os elementos do pacto de reciprocidade conjugal (ao atualizar seus valores nos seus discursos, tais como a presença dos seus maridos), elas jogam com seus termos e negociam sua ordem. $\mathrm{O}$ que dota de sentido este jogo de negociações são os atributos de gênero que conformam a "mulher valente" ${ }^{19}$, um feminino

gênero. Tanto o homem, quanto a mulher, para serem socialmente "respeitáveis" e reconhecidos como tais necessitam estar em relação, o que indica uma negociação constante entre os pares. FONSECA, Claudia. Aliados e Rivais na Família: o conflito entre consangüíneos e afins em uma vila porto-alegrense. Revista Brasileira de Ciências Sociais, São Paulo, vol. 2, nº 04, 1987 e Cavalo Amarrado Também Pasta: honra e humor em um grupo popular brasileiro. Revista Brasileira de Ciências Sociais. São Paulo, no 15, 1991; SARTI, Cynthia. Reciprocidade e Hierarquia: Relações de Gênero na Periferia de São Paulo. Cadernos de Pesquisa, São Paulo, n 70, 1989; ZaluAR, Alba. A Máquina e a Revolta: As organizaçóes populares e o significado da pobreza. 2a. edição, São Paulo, Brasiliense, 1994.

${ }^{19}$ De acordo com Fonseca e Paim, "mulher valente" - um modelo de feminino típico dos grupos populares urbanos porto-alegrenses - é aquela que, ao perceber uma crise na sua relação conjugal, lança mão de inúmeros recursos a fim de manter o "seu homem" e a unidade da sua família. Os casos analisados pelas autoras registram situações em que mulheres enganadas pelos seus maridos se utilizam de inúmeras estratégias - enfrentando as amantes, por exemplo além de transgredirem códigos sociais - saindo à noite desacompanhadas, por exemplo - a fim de manterem a sua relação conjugal. A mulher que faz diligências com este intuito não só dispõe de legitimidade, como também é valorizada socialmente pela sua valentia, atributo culturalmente associado ao masculino. No caso das PLPs, foram detectadas inúmeras situações em que os atributos de "mulher valente" eram acionados não apenas nos casos de traição, mas também em situações que ameaçam seu laço conjugal pela sua militância política. Ver FONSECA, Claudia. A mulher valente: gêneros e narrativas. Revista Horizontes Antropológicos: Gênero, Porto Alegre, n 1, 1995; PAIM, Heloísa Helena Salvatti. Vivendo como amante de um homem casado: entre a legitimidade e a ilegitimidade das uniões extraconjugais. Dissertação de Mestrado 
específico revelado pelas PLPs, que dá sustentação à sua militância política.

Os principais pontos de jogo e negociação com os termos do pacto de reciprocidade conjugal são: postura jocosa frente à possibilidade de abandono pelos seus maridos, a recusa no desempenho das tradicionais obrigações femininas e o constante contato com os mais diferentes homens.

Uma das peculiaridades deste grupo está na jocosidade com que tratam a possibilidade de serem abandonadas pelos seus maridos, devido a sua intensa agenda de reuniões políticas. Não raro, se divertiam com estas situações. O cotidiano do grupo pesquisado era marcado por inúmeras atividades, muitas delas noturnas. Numa das primeiras reuniões em que as acompanhei, comentei sobre o avançado da hora e questionei se seus maridos não se incomodavam com o fato de elas terem passado o dia todo fora de casa e de estarem retornando tão tarde. Eneida ${ }^{20}$, divertindo-se com a minha preocupação, respondeu-me: "Com a gente é assim mesmo... Não paramos em casa! Vai lá e diz para os teus colegas que os maridos destas mulheres já estão deixando delas por que elas não param em casa!" Para a minha surpresa, o inusitado de tal afirmação causou acessos de riso do grupo de mulheres com quem estávamos.

Associado a esta postura conjuga-se uma espécie de recusa ao desempenho de determinadas obrigações tradicionalmente femininas - cuidado da casa e dos filhos - em favor da sua participação política. Nas conversas entre o grupo, tensões entre os casais era um tema recorrente. Esta tensão pode ser resumida na acusação dos seus maridos de estarem sempre "na rua batendo perna à toa", atitude que parece cobrar um tipo de postura congruente com o que é esperado das mulheres dentro de um

em Antropologia Social, Universidade Federal do Rio Grande do Sul, Porto Alegre, 1998, 180p.

${ }^{20}$ Os nomes são fictícios. 
Relações de gênero no campo político

determinado universo de valores - ficar em casa, cuidando dos filhos e afazeres domésticos.

A forma como abordavam as tensões indica que estas mulheres se recusavam a estas obrigações. De fato, no cotidiano das PLPs, repleto de reuniões e atividades extra-domésticas, restava-lhes pouco tempo para os cuidados da casa e dos filhos. Para isto, contavam com o apoio de sua parentela - mães, irmãs, cunhadas, sobrinhas e comadres são acionadas enquanto as PLPs estão nas suas cotidianas atividades extra-domésticas.

Contar com a ajuda das mulheres de suas redes, por um lado, aponta para a negociação dos termos do pacto de reciprocidade conjugal, por outro, revela a aceitação da sua atividade política, das conseqüências que acarreta e, também, a inclusão destas mulheres nas suas redes de relações sociais. Extrapolando um pouco o escopo interpretativo, este dado também parece sugerir que esta forma de participação política é percebida como uma possibilidade para as mulheres das camadas populares urbanas. Fato que viabiliza um outro modelo de militância política, diferente da "maternidade militante". ${ }^{21}$

$\mathrm{O}$ fato de estarem sempre na rua, remete ainda ao enfrentamento de outro importante elemento constituidor do pacto de reciprocidade conjugal: a evitação masculina. Nas suas atividades políticas cotidianas, fundamentalmente extradomésticas, elas se inseriam num universo de valores regido pelo masculino e em contato com diferentes homens. A maioria dos espaços de participação política, em especial aqueles que se referem ao âmbito da política comunitária, são ocupados majoritariamente por homens.

No entanto, como já mencionado, mesmo desafiando os termos do pacto de reciprocidade conjugal, as PLPs referendam alguns de seus elementos, como a garantia da presença dos seus homens nas suas vidas. A referência a esta presença é um dos

${ }^{21}$ Alvarez, Sonia. Politizando as relações de gênero e engendrando a democracia. In: StEPAN, A. (ed.). Democratizando o Brazil. Op. cit. 
fundamentos do seu modelo de feminilidade e, especialmente, é onde se assenta sua imagem de "mulher respeitável", critério importantíssimo para o desempenho de suas atividades políticas.

A tensão produzida pela convivência entre diferentes valores $e$ atributos de gênero caracteriza o modelo fluído e contingente de feminilidade atualizado pelas mulheres pesquisadas. É com os atributos de gênero que informam este modelo de feminilidade que as PLPs entrarão no jogo das relações políticas.

\section{O jogo político: negociando relações de gênero nas relações políticas}

A partir do argumento de que o próprio campo político é dotado de certos atributos de gênero, culturalmente associados ao masculino e da afirmação de que o grupo pesquisado, ao entrar no campo político, traz consigo um determinado repertório de valores de gênero, cabe agora analisar como estes diferentes atributos de gênero interagem $e$ quais são os resultados produzidos nesta interação.

Uma forma eficaz de analisar estas interações pode ser o enfoque às micro-relações estabelecidas pelo grupo pesquisado no campo político, o que permite colocar em relevo diferentes alteridades que fazem parte do, e constituem o, próprio campo. No embate e negociação entre estas alteridades, percebe-se a utilização contextual de diferentes atributos $e$ a produção de sentidos de gênero. Esta característica de dinamicidade institui a fluidez e a contingência que parecem definir as relações de gênero que incidem sobre o campo do político no contexto pesquisado.

A fim de elucidar estas questões $e$ analisar os sentidos de gênero produzidos na prática política cotidiana do grupo, resgato três situações que representam diferentes espaços semânticos do contexto político de Porto Alegre, ressaltando as relações políticas que são estabelecidas em cada contexto específico $e$ as disputas de poder e de gênero implicadas nestas relações. 
Relações de gênero no campo político

\section{Situação I - na busca por um lugar no partido político, ou aqui sou feminista!}

O grupo pesquisado opõe-se fortemente ao fato de serem identificadas como feministas. ${ }^{22}$ Esta oposição prende-se a uma determinada concepção de feminismo que se encerra nas idéias de "ter alergia aos homens, de ser uma luta contra os homens"; elementos que são incongruentes com o modelo feminino "mulher valente". ${ }^{23}$ No entanto, esta oposição revelou-se contingente.

Numa reunião de articulação para as prévias da eleição das secretarias do partido, ao qual é filiada a PLP Anete, presenciei o seu descontentamento com relação ao lugar que ocupava ali. A PLP buscava compor alianças com uma das correntes do partido para fortalecer seu projeto de fundação de uma Secretaria da Mulher no partido. Num discurso inflamado, Anete menciona estrategicamente sua insatisfação com um dos vereadores da corrente hegemônica do partido:

\footnotetext{
${ }^{22}$ Sobre a oposição entre o ser feminina e o ser feminista estabelecida pelas PLPs e a concepção do ser feminista como uma categoria acusatória, ver BONETTI, A. L. Eu não sou feminista, sou feminina! Não tenho alergia a homens. Algumas notas sobre relações de gênero $e$ atuação política entre mulheres de grupos populares porto-alegrenses. Seminário Internacional Fazendo Gênero 4 Cultura, Política e Sexualidade no Século XXI, Florianópolis/SC, 2000.

${ }^{23}$ Esta associação entre feminismo e "alergia a homens" é herdeira do estereótipo presente no imaginário da sociedade brasileira construído, sobretudo, na década de 70 por correntes políticas que se opunham à emergência do movimento feminista no país. Ver GOLDBERG, Anette. Feminismo e autoritarismo: a metamorfose de uma utopia de liberação em ideologia liberalizante. Dissertação de Mestrado em Ciências Sociais, Universidade Federal do Rio de Janeiro, 1987, 200p. Em grande medida, algumas correntes feministas reafirmam este estereótipo ao constituírem os homens como um bloco de opositores, conforme discute Pontes no seu estudo sobre o SOS-Mulher de São Paulo. PONTES, Heloísa André. Do Palco aos Bastidores: o SOS - Mulher (SP) e as Práticas Feministas Contemporâneas. Dissertação de Mestrado em Antropologia Social, Universidade Estadual de Campinas, 1986, 178p.
} 
Eu falei para o Teodoro ${ }^{24}:$ "Onde está o meu espaço? Como vou trabalhar aqui no partido se não tem espaço para o meu trabalho!" Ele sempre soube que o meu trabalho é com a mulher. E eu sou feminista, ele sabe disso. Esse partido está muito machista para o meu gosto. Onde estão as mulheres? Só tem homem na executiva! O que é isso? Todos os partidos têm um fórum, um núcleo da mulher. Olha só o PT! Só o PSB não tem. Isso está errado, nós temos que mexer nisso. Eu sou promotora, trabalho com a mulher $e$ o Teodoro sabe disso. Em todos os lugares tem uma de nós representando: no PT tem, no COMDIM (Conselho Municipal dos Direitos da Mulher), no fórum da mulher. Só no PSB que não. Isso não pode, tem que mudar.

Após vários dias de intensas articulações, a Secretaria da Mulher é fundada e Anete é eleita secretária geral. A despeito do sucesso de sua empreitada política, é interessante notar a habilidade demonstrada por Anete ao fazer um uso estratégico e contextual de sua identificação com o feminismo. Em outra situação, ao ser por mim questionada sobre a sua "ambigüidade" - ora ela se dizia feminista e ora não -, ela explicou:

feminista no meu sentido, quando eu digo é uma coisa. Eu, que estou envolvida na questão política, na militância em partidos de esquerda, PDT, PSB, PT, PCdoB, a maioria dos cargos é dos homens. As mulheres, só na suplência. Então é disso que eu falava. Eu vou me juntar com a juventude do partido e formar uma secretaria de mulheres, que se chamaria feminista, por ter mais mulheres... Para participar mais mulheres, para discutir o espaço da mulher na política, para ter mais mulheres exercendo cargos... Porque eu, como promotora (PLP), estou a serviço da mulher. Não posso ficar calada vendo o machismo. Está muito devagar a participação da mulher na política. Quando eu falo o termo

${ }^{24}$ Vereador, ao qual Anete é ligada, eleito pelo PSB, ex-integrante do PT. 
Relações de gênero no campo político

feminista é isso. Quando eu estou em qualquer fórum, eu procuro sempre defender a questão da mulher. Eu estou ali representando as demais mulheres, os direitos, o respeito, a igualdade junto com os homens. Eu não sou uma feminista que não gosta de homem. Gosto de homem sim. Desde que o homem não aprecie só o sexo, mas goste também da minha defesa em prol das mulheres.

A explicação denota que a utilização da categoria "ser feminista" é contextual e articula determinados atributos de gênero (como gostar de homens, por exemplo). O depoimento de Anete evidencia um uso estratégico desta categoria de forma a se adequar aos seus propósitos políticos, revelando sua pretensão de realizar um projeto ao mesmo tempo político e pessoal de alcançar um lugar de destaque para si. Anete demonstra um excelente domínio dos códigos que regem aquele espaço semântico $e$ os manipula para a concretização de seus projetos. Ela utiliza uma categoria que sabe ter um alto valor naquele contexto: se assume feminista; muito embora seja uma feminista "diferente", de acordo com uma determinada concepção de feminilidade. ${ }^{25}$

Ao se identificar, contextual e estrategicamente, com a categoria feminista no âmbito do seu partido político, Anete manipulou diferentes atributos de gênero (encerrados no "ser feminista" e no "ser uma feminista diferente") a fim de negociar as relações políticas e de poder dentro daquele espaço. Com isto, ela

\footnotetext{
${ }^{25}$ Este movimento de utilização de categorias do feminismo foi identificado também por outras pesquisadoras, muito embora interpretem este fenômeno de forma distinta. Meu enfoque privilegia o discurso êmico, o domínio de códigos culturais diferenciados e seu uso contextualmente estratégico. Em contrapartida, outras perspectivas interpretam este uso de categorias do feminismo, por outras atrizes do movimento mais amplo de mulheres, como uma forma de adesão ao movimento feminista, embora ressignificado. Ver AlvAREZ, Sonia. A "Globalização" dos feminismos latino-americanos: tendências dos anos 90 e desafios para o próximo milênio. In: AlvAREZ, S. et alii. Cultura e política nos movimentos sociais latino-americanos. Belo Horizonte, Editora da UFMG, 2000.
} 
estabeleceu uma relação de gênero particular e contigente, como se pode notar ao se contrastar tal situação com a que se segue.

\section{Situação II - entre feministas, ou aqui sou popular!}

A segunda situação diz respeito a uma reunião no Conselho Municipal dos Direitos da Mulher (COMDIM) ${ }^{26}$, importante espaço político no campo do movimento de mulheres. Resultado de lutas feministas, o CONDIM ainda mantém as características do grupo de fundação, sendo hegemônica e hierarquicamente constituído por "feministas históricas" ${ }^{27}$ Muitas PLPs fizeram parte, em algum momento, deste conselho, entretanto, ocuparam posições periféricas na sua estrutura, na maioria das vezes como suplentes das conselheiras titulares.

Em clima descontraído, as participantes demonstravam uma certa intimidade ao se referirem ao nome próprio de cada

\footnotetext{
${ }^{26} \mathrm{O}$ COMDIM constitui-se a partir do Fórum de Mulheres de Porto Alegre. Este conselho é composto por sete conselheiras titulares representantes da administração pública municipal e quatorze conselheiras titulares representantes de órgãos e entidades de mulheres da sociedade civil. Além destas, há a mesma quantidade de conselheiras suplentes. Dentre as 42 conselheiras, somente as titulares podem se candidatar a cargos da direção executiva.

${ }^{27}$ Grossi define as "feministas históricas" como "aquelas que participaram das mobilizações do período conhecido como a 'primeira década da mulher', entre 1975 e 1985, engajadas no movimento feminista 'autônomo' há mais de 15 anos e que estão hoje na meia-idade. Estas mulheres, que no período da sua adesão ao feminismo, no final dos anos 70 , militavam nas suas horas vagas em diferentes grupos feministas sem receber nenhuma remuneração, se tornaram progressivamente assalariadas da causa das mulheres. Este assalariamento deuse de diferentes formas: tanto pela profissionalização de alguns antigos grupos autônomos que se transformaram em reconhecidas organizações não governamentais, quanto pela criação de espaços feministas em diferentes instituições, como no serviço público e na universidade". GROSSI, Miriam. Feministas históricas e novas feministas no Brasil. Antropologia em Primeira Mão, nº 28, Florianópolis, 1998, p.5.
} 
Relações de gênero no campo político

"companheira", exceto as duas PLPs presentes, referidas como as "companheiras PLPs". ${ }^{28}$

As PLPs Raquel e Rute pouco opinavam na discussão, permanecendo numa posição de observação com um ar entediado. Uma das decisões tomadas foi a formação de uma comissão eleitoral. Enquanto se discutia o formato da comissão, as duas PLPs conversavam baixinho entre si, segundos depois, Raquel se ofereceu para participar da comissão.

Ao final da reunião, Rute comentou discretamente comigo: "viste como só tem madame aqui?" Aproveitei a deixa e perguntei se elas, como PLPs, comporiam uma chapa para concorrer à direção executiva do conselho. Ela respondeu negativamente, já que Raquel, como conselheira titular, seria a única que formalmente poderia se candidatar, mas não estava disponível para a atividade naquele momento. As outras PLPs participantes do COMDIM eram apenas suplentes e, por isto, não poderiam se candidatar. Perguntei por que elas tinham ficado de suplentes. Ela contou, em tom de indignação,

foi uma sacanagem o que elas [as madames] fizeram. $\mathrm{Na}$ semana passada quando a gente chegou para a posse [das 42 conselheiras do COMDIM] já estava tudo decidido quem ia ser titular e quem ia ser suplente. A gente reclamou, mas não conseguiu mudar nada. Já estava decidido quem eram as conselheiras. [Raquel completou] Este é um lugar de elite.

O tom de indignação presente na narrativa das PLPs se deve ao fato de não se reconhecerem como pertencentes a este espaço político de defesa da mulher e, mais especificamente, de se sentirem excluídas dos processos de decisão - seja pela identificação do lugar como um espaço privilegiado, ocupado por

${ }^{28} \mathrm{Na}$ ocasião, acompanhei as PLPs Raquel e Rute na reunião, cuja pauta era a discussão do regimento do conselho, o processo eleitoral para o conselho e a definição da data da eleição. 
mulheres de outra pertença social que não a sua, seja pelo desejo de ocuparem lugares de destaque nestas instâncias.

Esta situação indica um embate entre diferentes femininos que disputam um mesmo lugar de poder, instaurando uma nova configuração de relações de gênero entre diferentes femininos. Quais são os atributos de que as PLPs lançam mão para demarcarem a sua especificidade?

Ao acusar os outros femininos, com os quais estão em relação, de "madames, elite", as PLPs utilizam atributos de classe. Articulam aos atributos de gênero, atributos de classe. Contudo, não se trata de qualquer atributo; elas jogam contrastivamente com aqueles que sabem ter um grande valor político local - ser "popular".

Neste sentido é esclarecedora a explicação das PLPs Eneida e Anete, sobre sua inserção de classe:

Eneida: é por isso que nós somos populares, para andar com barro até a cintura, toda embarrada, molhada. Lembra, Anete, que o sargento queria saber?

Anete: Ah, é. O sargento ali do posto queria saber o por quê do popular no promotoras legais populares.

Eneida: Ele não entende por que nós somos populares, já que todas as promotoras que ele conhece não são populares. Eu expliquei para ele que era por que a gente trabalhava desde a Santo Antônio até a Lomba [vilas da periferia de Porto Alegre]. Para isto tem que botar o pé no barro mesmo, andar pela comunidade. Nós não somos de gabinete. As que ele conhece são de gabinete, ficam na sua salinha, não botam o pé no barro como nós.

Para as PLPs o importante é "ter a prática, vivenciar os problemas da comunidade". Para elas, "ser popular" marca, neste contexto, positivamente sua identidade política e de gênero, o que parece revelar um domínio ímpar dos códigos que regem o cenário político de Porto Alegre, onde o termo "popular" tem alto valor político. Num contexto marcado pela supremacia do 
Relações de gênero no campo político

"popular" - no qual a definição da própria administração municipal é perpassada pelo "popular" e, com isto, a participação política e a cidadania são significadas pelo "popular" - nada mais estratégico do que carregar consigo a marca, a própria encarnação do "popular".

Desta forma, as PLPs procuram se afirmar como sujeitos políticos, na busca de posições definidas no contexto político específico do COMDIM. Estas posições são "princípios organizadores embutidos de práticas materiais $e$ arranjos institucionais [que se dão] em relação constitutiva com um outro". ${ }^{29}$ No caso em questão, se dão em relação às "mulheres de elite", as feministas históricas que dominam as posições de poder no COMDIM e com quem as PLPs disputam. Neste contexto, identificar-se como feminista passa a não fazer sentido, como aponta a PLP Lia:

Feminista eu acho já uma questão muito teórica, elas usam muito a teoria. Por exemplo o Conselho Municipal dos Direitos da Mulher está tão longe, tão longe das mulheres populares. São advogadas, são jornalistas, médicas que têm um assunto teórico, sabe? Eu acho que é muito teórico, fazem muito relatório teórico. Mas tu não vês elas na prática. Tu não vês esses movimentos dentro das vilas. E tu também não vês nem elas abrirem muito espaço. Eu acho que são mulheres que lutam mais pelos direitos das mulheres feministas, independente dessa coisa de defender todas as mulheres. Para mim, feminista é algo, sei lá, uma pessoa teórica. Só tem estudo do que é a mulher. Digamos, seria diferente do que é uma mulher mulherista, que são as questões reais da mulher. Então, feminismo para mim seria alguém de classe A ou $\mathrm{B}$.

As PLPs se distinguem das feministas, "as madames de elite" do COMDIM, ao articularem nesta relação de poder e de gênero

${ }^{29}$ ButLER, J. Fundamentos Contingentes... Op. cit., p.24. 
um atributo de classe. Nesta relação, as PLPs se definem como mulheristas - mulheres populares que representam os interesses das mulheres populares. Neste jogo de alteridades, que põe em relevo distinções de gênero, as PLPs põem em xeque uma pretensa unidade entre "irmãs de gênero" 30 ao introduzirem uma distinção que passa, sobretudo, pelo recorte de classe no desempenho do jogo político. Aqui se revela mais uma negociação de relações de poder e de gênero nas relações políticas de forma contextual e contingente.

\section{Situação III - quando o outro também é popular}

Como terceira e última situação resgato outro importante espaço político freqüentado pelo grupo pesquisado: as assembléias do Orçamento Participativo (OP). Neste espaço, as PLPs pesquisadas estabelecem outras relações políticas e disputam com outros sujeitos que compartilham da sua especificidade de classe, ou seja, também são populares. Como se diferenciam e se tornam particulares aqui? Lançando mão de outras estratégias, a partir da compreensão dos códigos que regem este espaço político. O jogo que as PLPs empreendem na inserção neste espaço implica na produção de outros significados de gênero. Estas estratégias são explicitadas na definição deste espaço político pela PLP Anete:

Entre liderança comunitária é uma disputa de poder só. Eu que estou nisso vai fazer 11 anos agora, sei bem como é. As pessoas brigam por tudo, para ser representante de rua, delegado do Orçamento Participativo [diferentes instâncias de participação no processo do OP], por tudo. É muita disputa por poder. E por isso tem muita fofocagem. Aí que tu tens que ficar de boca fechada e falar o menos possível. Tu ganhas mais, se ficar só escutando, observando. Esse

${ }^{30}$ Fox-GenOveSE, Elizabeth. Para além da irmandade. Revista Estudos Feministas, nº 0, Rio de Janeiro, 1992, pp.31-56. 
Relações de gênero no campo político

meio de liderança comunitária dá muita falação, tem que estar se cuidando.

No espaço político do $\mathrm{OP}$, segundo Anete, a disputa de poder está intrinsecamente associada à fofoca, contextualmente entendida como um recurso de controle dos termos da disputa propriamente política. Apropriar-se deste recurso e jogar com seu funcionamento parece ser a possibilidade de lograr um lugar de destaque.

$\mathrm{Na}$ contra-face da fofoca está também outro código igualmente poderoso, recorrentemente utilizado pelas PLPs - a "troca de homenagens" -, que se traduz, na prática, como um jogo público de troca de elogios e deferências entre diferentes pessoas. Uma das partes envolvidas ressalta as virtudes da outra publicamente e a elogiada deve deixar transparecer modéstia frente aos elogios recebidos. No âmbito privado, críticas à parte elogiada são recorrentes e fazem parte do mesmo jogo.

Este jogo apresenta muitas semelhanças com a forma como se estruturam as relações sociais de gênero numa vila popular de Porto Alegre, descritas por Fonseca. ${ }^{31}$ Segundo esta antropóloga, naquele contexto, "a honra figura como elemento simbólico chave que, ao mesmo tempo, regula o comportamento e define a identidade dos membros do grupo". ${ }^{32}$ Mais especificamente, as trocas de homenagens públicas eram um dos elementos constituidores do prestígio e da honra masculinas. Em contrapartida, a fofoca figura como elemento socialmente controlador da honra feminina.

A utilização tanto da fofoca quanto da troca de homenagens eram recursos amplamente utilizados pelo grupo pesquisado nos mais diferentes espaços políticos pelos quais circulavam. Um caso exemplar aconteceu entre a PLP Anete e Cinara, PLP que se

${ }^{31}$ FonSECA, Claudia. Feminino, masculino e formas de poder... Op. cit.

${ }^{32}$ ID., IB., p.2. 
encontrava afastada do exercício desta atividade e por este motivo muito criticada pelo grupo de PLPs.

Em determinada reunião do OP, Anete chamou Cinara para apresentá-la a mim. Com um certo ar de deferência, desdobrou-se em elogios a sua colega, enfatizando as atividades em que Cinara estava envolvida. A elogiada, entre sorrisos, salientou que vinha trabalhando muito e passou a me relatar detalhadamente suas atividades. Quando Cinara se afastou, Anete passou a desconstituir a imagem de liderança e de abnegação que a colega empenhou-se em me demonstrar.

À luz da análise de Fonseca, esta situação vivenciada pelas PLPs indica a utilização, no domínio da política, de estratégias reguladoras do prestígio social do masculino e do feminino dentro do universo de valores das camadas populares. Tanto a troca de homenagens quanto a fofoca são componentes fundamentais do jogo político naquele contexto. As PLPs pesquisadas utilizam estes artifícios para estabelecer suas relações políticas e, através deles, jogam com diferentes atributos de gênero para negociar as relações de poder dentro do espaço político do OP.

O domínio destes códigos e sua habilidade em utilizar estes diferentes recursos também pode ser verificada na maneira como atribuem sentido ao jogo político que empreendem. Para designar sua prática política, as PLPs, freqüentemente, empregam termos como "força, luta, briga, bater, dar pau". Termos estes que fazem parte de um repertório simbólico associado a elementos como agressividade, virilidade, atributos culturais relacionados ao masculino na nossa cultura.

Estes termos são utilizados em contextos onde se tem um embate entre questões políticas divergentes - no OP, nas reuniões das coordenações do SIM, nos conselhos municipais ou, ainda, nos partidos políticos dos quais participam -, ou seja, na ação política propriamente dita. Antes das reuniões do OP, a PLP Alice costumava dizer: "já estou me aprontando pra brigar hoje lá". Numa das reunióes em que a acompanhei, Alice foi a única 
Relações de gênero no campo político

mulher a se candidatar como representante do Conselho Popular do seu bairro na Comissão de Transportes Urbanos.

Frente a sua candidatura, os homens presentes, contrários a sua iniciativa, argumentaram sobre a necessidade de ter experiência no ramo dos transportes para ocupar tal cargo. Alice rapidamente contra-argumentou: "se é para ir lá e brigar, pode deixar comigo, isto eu sei fazer"! Ou seja, da ação propriamente política ela entendia, o que parecia ser o requisito necessário para o desempenho de tal função. No entanto, Alice não foi eleita para o cargo.

Neste contexto político, no qual as PLPs se enfrentavam com diferentes femininos e diferentes masculinos, elas demonstraram mais uma vez a habilidade no domínio e negociação dos códigos que regiam tal espaço na busca de nele se afirmarem. Elas transitaram entre diferentes atributos de gênero, negociando a cada momento uma nova relação de gênero e de poder ao estabelecerem suas relações políticas.

\section{Considerações finais}

O início deste artigo colocava em questão se a crescente e visível presença de mulheres no mundo da política implicaria numa transformação dos valores que dotam de sentido de gênero o campo político. Por trás deste questionamento estava a hipótese de que esta crescente presença traria consigo a introdução de novas e diversas relações de gênero no campo político, possibilitando transformações nas relações de poder que estariam embutidas nas relações políticas e de gênero que o constituem.

A reflexão sobre este questionamento se apoiou em pesquisa etnográfica realizada junto a um grupo de mulheres das camadas populares de Porto Alegre, ativistas em Direitos Humanos das Mulheres. A potencial riqueza analítica da experiência de participação política do grupo estudado permite formular novos esquemas interpretativos para a compreensão da relação entre política e relações de gênero. As diferentes situações 
protagonizadas pelo grupo pesquisado indicam que as relações de gênero se imiscuem nas relações políticas, jogando com diferentes atributos de gênero de forma contextual e contingente.

O caráter conflitivo, que marca as disputas políticas no caso analisado, aponta a desconstrução de uma suposta e nostálgica política no feminino, que seria caracterizada pela cooperação $e$ pela solidariedade, elementos constituidores de uma irmandade de gênero. As estratégias utilizadas pelas PLPs, os jogos empreendidos - de identificação e diferenciação entre femininos e masculinos, de proximidade e distanciamento e de apropriação $e$ negociação com os códigos que atribuem sentido aos espaços semânticos do campo político - denota a tensão entre alteridades que buscam legitimidade e reconhecimento neste campo.

Como salienta Taylor "àquilo a que somos chamados a reconhecer é a identidade única deste indivíduo ou grupo, aquilo que o diferencia de todos os demais". ${ }^{33}$ Mas que, no entanto, apenas se revela como única em relação a um outro, que é contigente, porque situado num contexto permeado por "conflitos, estratégias de legitimação e jogos de reconhecimentos" 34 , como o é o campo político.

Talvez aí se configure a possibilidade de transformação do campo político, introduzida pela presença destas atrizes sociais, o descortinamento do caráter conflitivo e de disputa que a relação entre diferentes femininos e masculinos impõe nas relações políticas. Através deste descortinamento, é possível vislumbrar a existência de diferentes vozes no campo político, as quais insistem em embaralhar as formulações consolidadas sobre relações de gênero e de poder.

${ }^{33}$ TAYLOR, Charles. The Politics of Recognition. In: Gutmann, Amy. (ed.) Multiculturalism: Examining the Politics of Recognition. Princeton/New Jersey, Princeton University Press, 1994, p.33.

${ }^{34}$ Barreira, I. e Palmeira, M. Introdução. In: Barreira, I. e Palmeira, M. (orgs.) Candidatos e candidaturas... Op. cit., p.7. 